\title{
Daytime preservation of surface-hoar crystals
}

\author{
Akiniro Hachikubo, Eizi Akitaya \\ Institute of Low Temperature Science, Hokkaido University, Sapporo 060, Japan
}

\begin{abstract}
Surface hoar growing for several clear and humid days were observed. During daytime, air and snow-surface temperature increased and relative humidity decreased, hence evaporation (sublimation) occurred at the snow surface. The amount of evaporation calculated using a bulk-transfer method suggests that the surface-hoar crystals which grew during the previous night should have disappeared but they were observed to survive on the snow surface even during the daytime. During the following night, new surface-hoar crystals formed on top of the older ones and grew even larger. This result indicates that, although the surface-hoar crystals evaporated into the air during the daytime, snow grains beneath the surface were warmed by solar radiation and evaporated to the air. They may partially condense into the surface-hoar crystals and make up for the reduction in size. Depth-hoar crystals formed beneath the snow surface for several days and the surface layer, composed of both types of hoar crystal, showed a very weak shear strength.
\end{abstract}

\section{INTRODUCTION}

Surface-hoar crystals are formed by the deposition of water vapour on to a snow surface during clear nights. They have long been of interest to avalanche researchers (e.g. Perla and Martinelli, 1976), because after being buried by a subsequent snowfall, they often form a weak layer due to their lack of intercrystalline bonding and weak attachment to the original snow surface. Davis and others (1997) observed buried surface hoar and pointed out that well-developed surface hoar prevents subsequent snowfall particles from contacting the layer below. In addition, Lang and others (1985) have reported that after formation of surface-hoar crystals (size up to $40-50 \mathrm{~mm}$ ), they became a weak layer and the shear strength remained low for extended periods of time. Distinct buried layers of surface hoar represent typical sliding layers for slab-avalanche release. Therefore, it is important to study in detail meteorological conditions suitable for surface-hoar growth, in order to create an avalanche-forecasting system. In this paper, we report that surface-hoar crystals have survived on the snow surface even during daytime and have grown large over several days.

\section{OBSERVATION SITE AND OBSERVED ITEMS}

Observations were carried out in the winter of 1994 95. The site, located on a mountain ridge, is flat about $30 \mathrm{~m}$ around and near the avalanche-research station ( $240 \mathrm{~m}$ a.s.l.) of the Institute of Low Temperature Science, at the Teshio Experimental Forest of Hokkaido University, located in Toikanbet$\mathrm{su}$, northern Hokkaido, Japan. The station $\left(45^{\circ} \mathrm{N}, 142^{\circ} \mathrm{E}\right)$ is close to the Japan Sea (about $20 \mathrm{~km}$ distance) and the predominant wind direction in winter is southwest. Air temperature, humidity, wind speed, snow-surface temperature and vapour condensation were measured. Observational methods and instrumentation used have been described by Hachikubo and others (1994) and Hachikubo and Akitaya https://doi.org/10.3189/1998AoG26-1-22-26 Published online by Cambridge University Press
(1997). The surface temperature was measured using a copper-constantan thermocouple during night-time. In addition, since the thermocouple absorbed solar radiation and overestimated the surface temperature, we used an infrared radiation thermometer (HORIBA IT-340W; accuracy: \pm $2{ }^{\circ} \mathrm{C}$ ) during daytime. The latent-heat flux at the surface, which corresponds to the vapour-condensation rate or evaporation rate, was estimated by using a bulk-transfer method (Stull, 1988):

$$
E=-C_{\mathrm{e}} \rho u_{z}\left(q_{z}-q_{\mathrm{s}}\right)
$$

where $E$ is the water-vapour flux $\left(\mathrm{kg} \mathrm{m}^{-2} \mathrm{~s}^{-1}\right), C_{\mathrm{e}}$ is the bulktransfer coefficient of water vapour, $\rho$ is the density of air $\left(\mathrm{kg} \mathrm{m}^{-3}\right), u_{z}$ is the wind speed $\left(\mathrm{m} \mathrm{s}^{-1}\right)$ at a height of $z(\mathrm{~m})$, and $q_{z}$ and $q_{\mathrm{s}}$ are the specific humidities at $z$ and the snow surface, respectively. The value of $2.9 \times 10^{-3}$, obtained from the field observations (Hachikubo and Akitaya, 1997), was used as $C_{\mathrm{e}}$. On the other hand, the vapour flux was also measured directly at night by weighting a $20 \mathrm{~mm}$ thick snow layer on an aluminum plate of $0.5 \times 0.6 \mathrm{~m}^{2}$ with an electric balance every 30 minutes. However, we could not obtain the vapour flux using this device during daytime, because the aluminum plate absorbed solar radiation and overestimated evaporation.

\section{OBSERVATIONAL RESULTS}

In the following, two cases of surface-hoar growth are described.

\section{Case 1 from 26 to 28 December 1994}

It was almost clear during this period except for the morning of 27 December and the midnight of 27-28 December; surface hoar had formed during both nights. Figure 1 shows the air temperature $T_{\mathrm{a}}$ at $1 \mathrm{~m}$ height, the snow-surface temperature $T_{\mathrm{s}}$, relative humidity and wind speed at $1 \mathrm{~m}$ height 

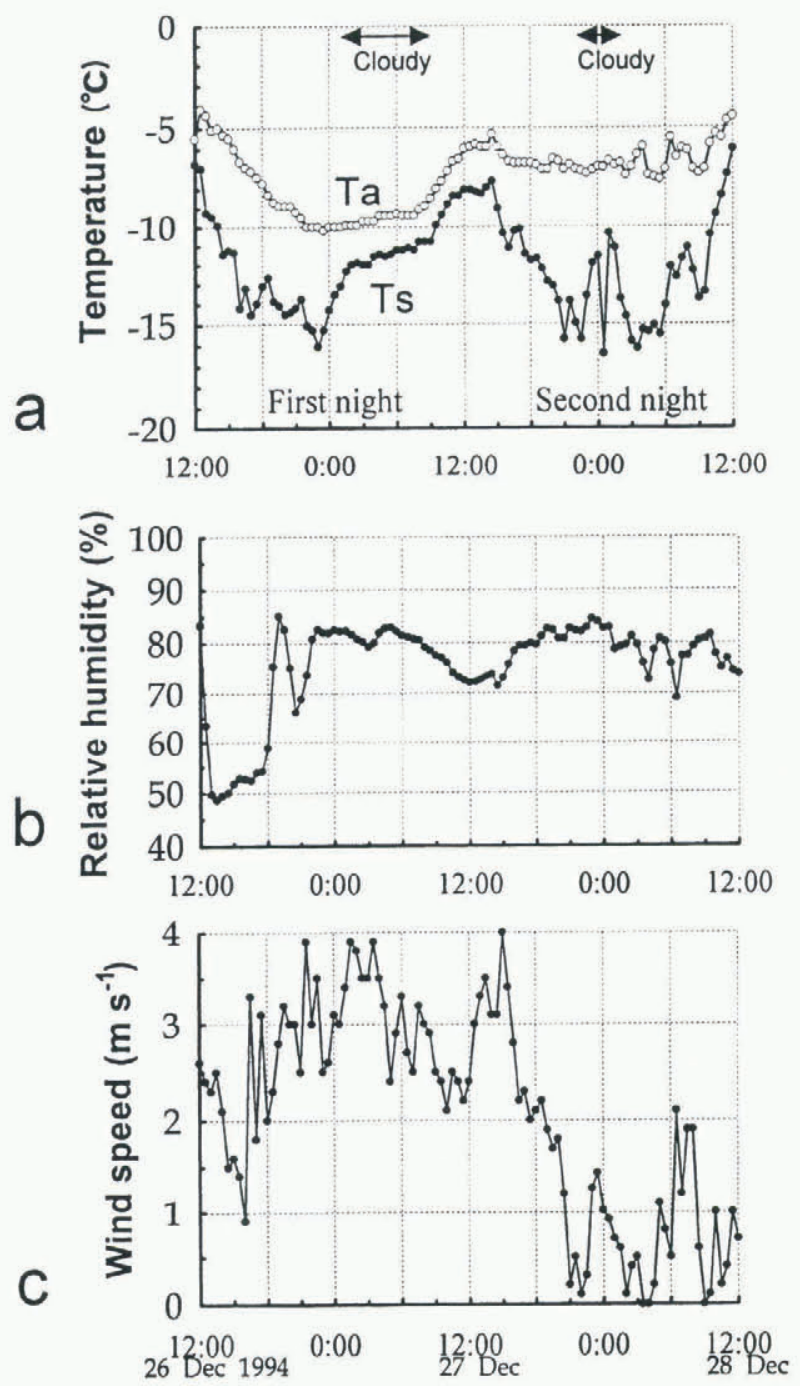

Fig. 1. Time variations of meteorological elements from 26 to 28 December 1994. (a) Air temperature $T_{\mathrm{a}}$ at $1 \mathrm{~m}$ height and snow-surface temperature $T_{\mathrm{s}}$. (b) Relative humidity at $1 \mathrm{~m}$ height. (c) Wind speed at $1 \mathrm{~m}$ height.

over time. $T_{\mathrm{s}}$ was always lower than $T_{\mathrm{a}}$ and the difference between $T_{\mathrm{a}}$ and $T_{\mathrm{s}}$ became larger during the nights. $T_{\mathrm{s}}$ increased under cloudy conditions due to the decreasing radiative cooling. Relative humidity was about $80 \%$ when surface hoar formed and did not decrease much even during the daytime of 27 December. Wind speed was less than $4 \mathrm{~m} \mathrm{~s}^{-1}$ and was quite low during the second night. Figure 2 shows the time variation of the latent-heat flux. The latentheat flux from the bulk-transfer method agreed fairly well with the value from the evaporimeter. However, the former was smaller than the latter during the second night when the wind speed was very low. It is probably because the three-cup anemometer underestimated the wind speed due to a specific starting wind speed of the device. Also, we could not take into account the effect of an intermittent turbulence which might occur in such a stable condition (Colbeck, 1988). From 18.30 on 26 December until 03.00 on 27 December, the total condensation of surface hoar was $74 \mathrm{~g} \mathrm{~m}^{-2}$, while the total evaporation from $03.30-15.00$ on 27 December was $62 \mathrm{~g} \mathrm{~m}^{-2}$. Therefore, the surface-hoar crystals formed during the first night were expected to have been almost eliminated. However, they survived on the snow surface and new hoar crystals developed on top of them during the second night. Figure 3 a shows a photomicrograph of the

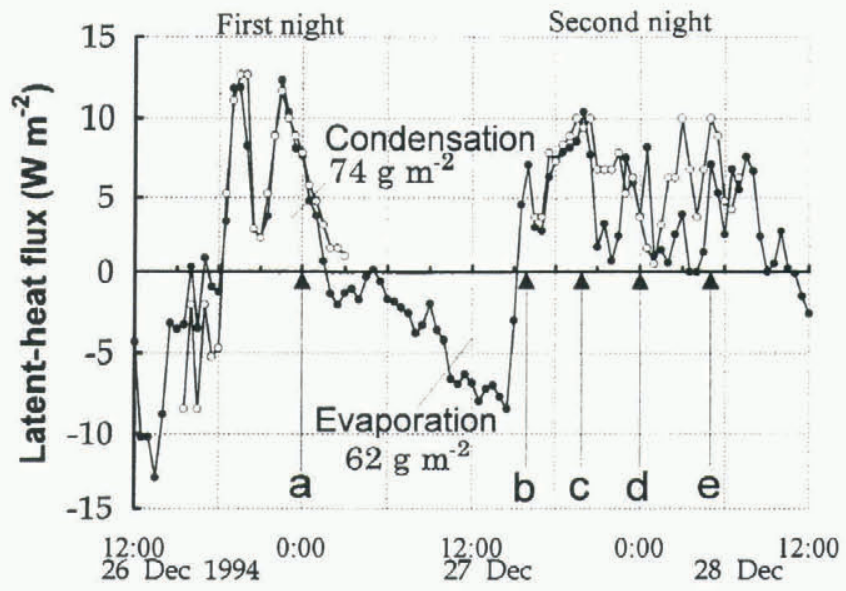

Fig. 2. Time variation of latent-heat flux from 26 to $28 \mathrm{De}$ cember 1994. •, bulk-transfer method, O, evaporimeter.

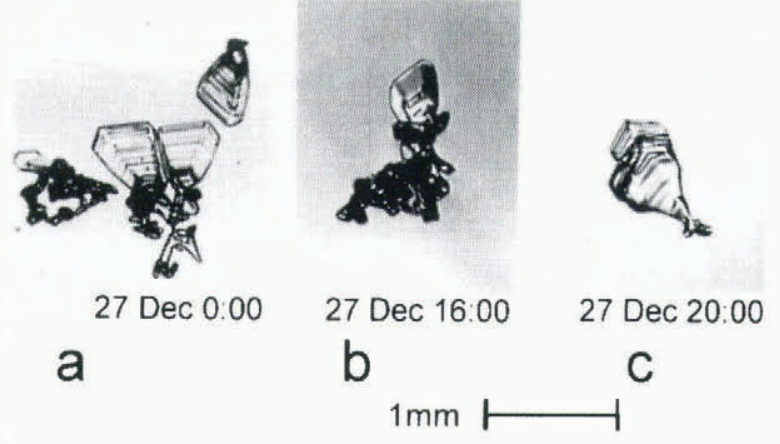

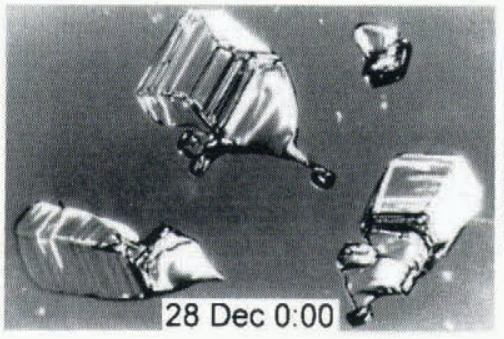

d

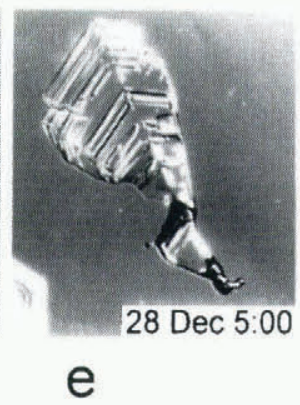

Fig. 3. Photomicrographs of surface-hoar crystals formed from 26 to 28 December 1994. (a) Surface-hoar crystals formed in the first night. (b) A surface-hoar crystal that survived during daytime and has been rounded by evaporation. (c)-(e) New crystals developed on the old ones during the second night.

surface-hoar crystals formed on a snow particle at the surface during the first night. Their size was less than $1 \mathrm{~mm}$ in diameter. Figure $3 \mathrm{~b}$ shows the "survived" crystal during the evening rounded by evaporation during the daytime. New crystals during the second night developed on the old ones and reached $3 \mathrm{~mm}$ in diameter (Fig. $3 \mathrm{c}-\mathrm{e}$ ).

\section{Case 2 from 23 to 26 February 1995}

Surface-hoar growth was observed during three clear and humid nights from 23 to 26 February. Variations of $T_{\mathrm{a}}, T_{\mathrm{s}}$, relative humidity and wind speed with time are shown in Figure $4 . T_{\mathrm{s}}$ was $5^{\circ}$ to $10^{\circ} \mathrm{C}$ lower than $T_{\mathrm{a}}$ at each midnight due to radiative cooling. Though the relative humidity decreased to $50 \%$ during the daytime of 25 February, it kept to more than $70 \%$ during the night. Except for the daytime on 24 February, the wind speed was less than $2 \mathrm{~m} \mathrm{~s}^{-1}$, which 
a
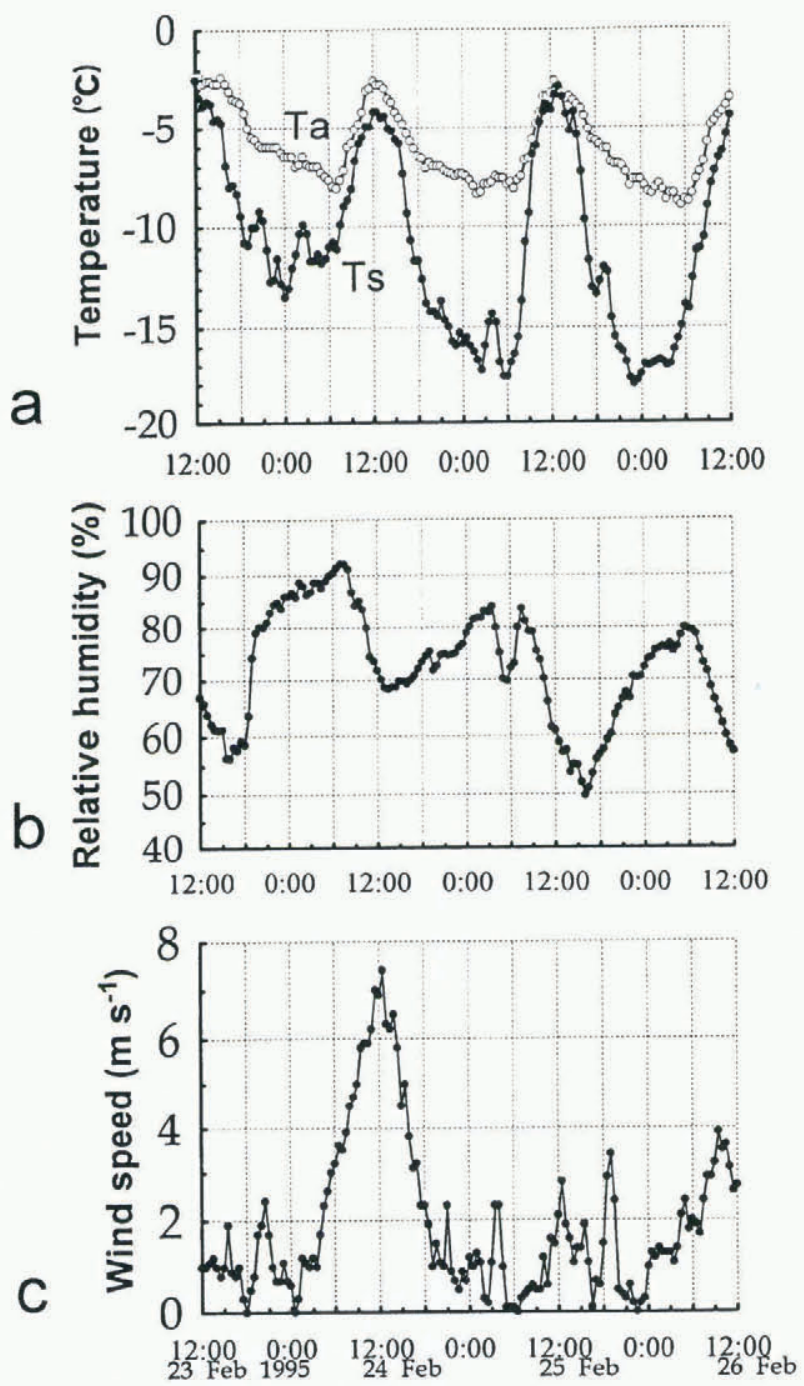

Fig. 4. Time variations of meteorological elements from 23 to 26 February 1995. (a) $T_{\mathrm{a}}$ and $T_{\mathrm{s}}$. (b) Relative humidity at $1 \mathrm{~m}$ height. (c) Wind speed at $1 \mathrm{~m}$ height.

corresponds to a suitable wind speed for surface-hoar formation (Hachikubo and Akitaya, 1997). Figure 5 shows the time variation of the latent-heat flux. Since we did not measure the latent-heat flux with the evaporimeter in this case, only that estimated from the bulk-transfer method is shown. Water vapour was deposited on to the snow surface and formed surface-hoar crystals during the night-time, whereas

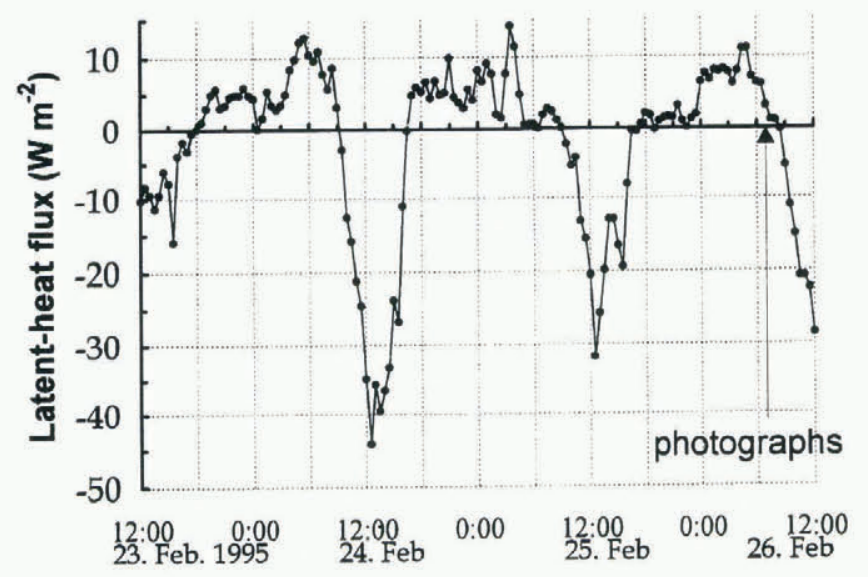

Fig. 5. Time variation of latent-heat flux from 23 to $26 \mathrm{Feb}$ ruary 1995.
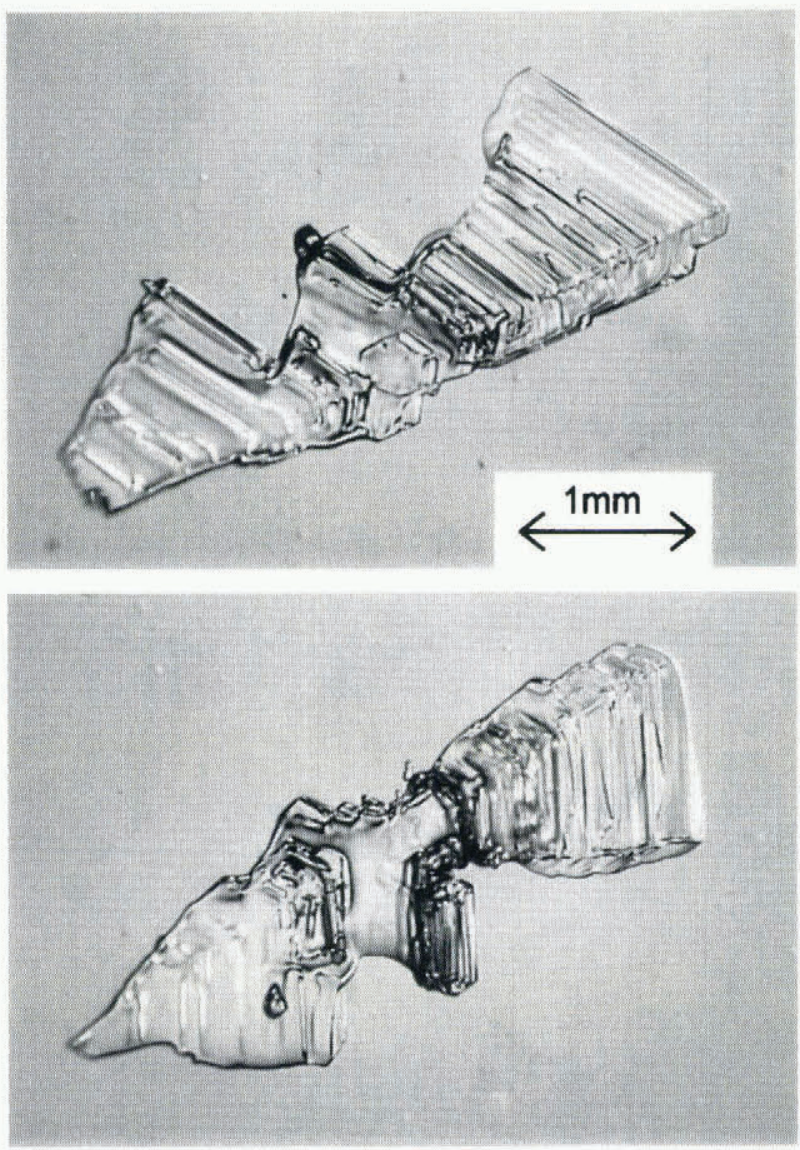

Fig. 6. Photomicrographs of surface-hoar crystals observed at 07.00 on 26 February. They consisted of three parts.

a large amount of evaporation was calculated during the daytime. So, we can again expect that the surface-hoar crystals, which grew during the first two nights, should have evaporated during the following daytime. Therefore, surface-hoar crystals found in the morning of 26 February should have formed due to vapour condensation only during the previous night. However, surface-hoar crystals observed at 07.00 on 26 February consisted of three parts (Fig. 6), which suggests that these crystals developed step-by-step during three nights.

On the other hand, since large temperature gradients developed during the night not only above but also below the snow surface, depth-hoar crystals grew beneath the surface. They began to form in the new snow on 22 February, and developed in the uppermost $10 \mathrm{~mm}$ as shown in Figure 7. On 27 February the upper region of $10 \mathrm{~mm}$ comprised surface-hoar and depth-hoar crystals. Shear tests on the sur-

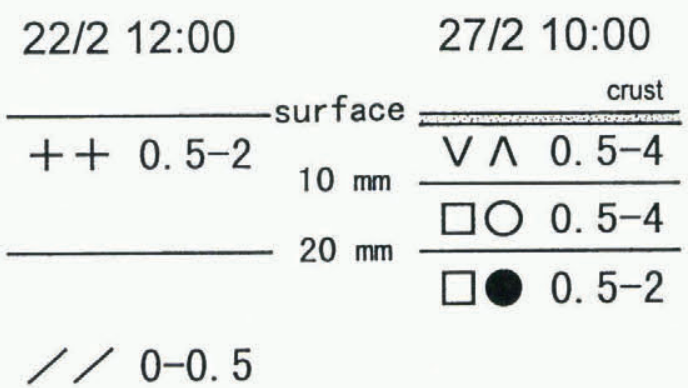

Fig. 7. Profiles of the snow-surface layer at 12.00 on 22 February and at 10.00 on 27 February 1995. 


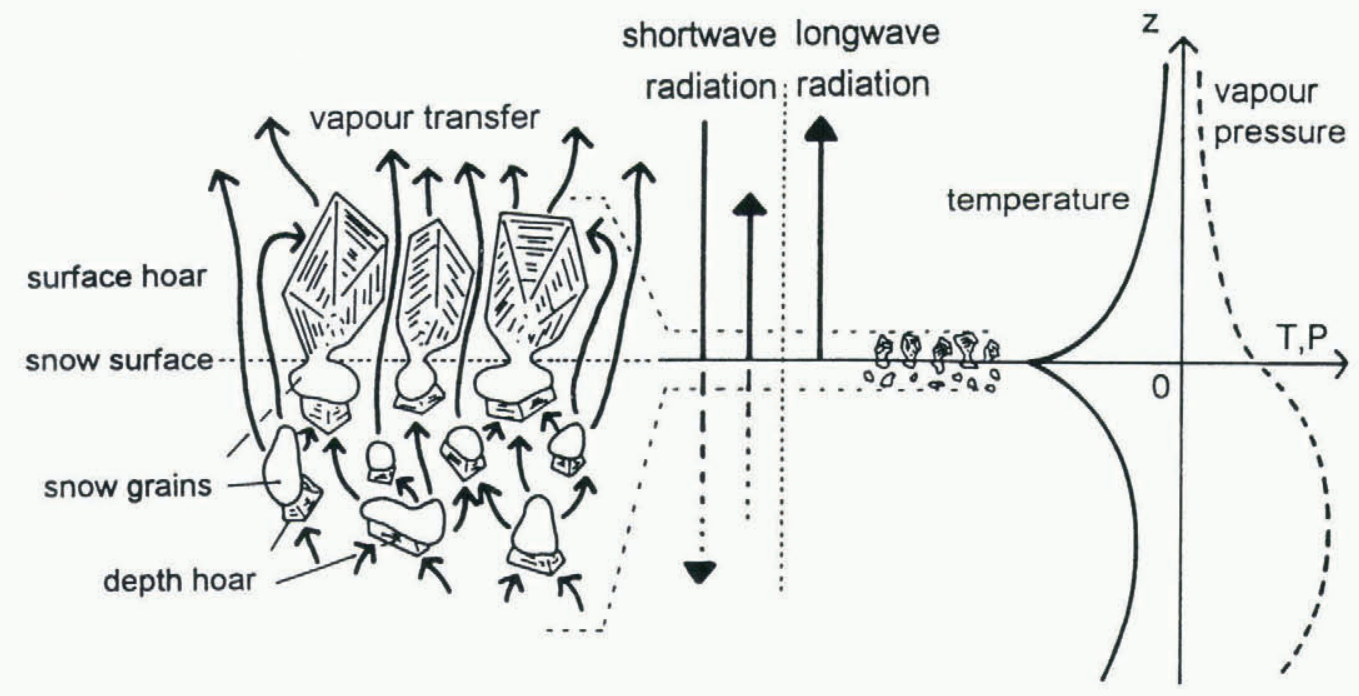

\begin{abstract}
Fig. 8. Schematic view of the vapour-transport process, radiative balance, and temperature-and the vapour-pressure profile near the snow surface during daytime.
\end{abstract}

face layer, which was composed of both hoar crystals, was done using a shear frame $\left(0.025 \mathrm{~m}^{2}\right)$ placed on the lightly crusted snow surface that formed on 26 February (Fig. 7). The shear-frame index of this layer was less than $100 \mathrm{~Pa}$ on 27 February. Since subsequent drifting snow eroded this layer, we could not obtain a variation of the shear strength with time.

\section{DISGUSSION AND CONGLUSIONS}

We observed that surface-hoar crystals survived on the snow surface during the daytime, although the amount of evaporation calculated from the bulk-transfer method was sufficient to evaporate them. First of all, we have to consider the radiative balance near the snow surface, which affects the thermal and vapour-pressure conditions. As Oke (1987) has noted, shortwave radiation is transmitted and absorption occurs within a volume rather than at a plane, and on the contrary, longwave radiation is absorbed and emitted at the snow surface. Therefore, during daytime, shortwave radiation warms beneath the snow surface while outgoing longwave radiation cools the surface-hoar crystals, as shown in Figure 8. From the profile of water vapour pressure in Figure 8, we can estimate the vapour-transport process near the snow surface; the water vapour, evaporated from snow grains beneath the surface where the vapour pressure is high, passes through the surface-hoar layer and escapes to the dry air, according to the vapour-pressure gradient. It probably deposits partially on the surface-hoar crystals.

Since the snow surface is porous and the density of the surface-hoar layer is extremely low, the snow-surface temperature measured by the infrared-radiation thermometer can be influenced by the temperature of the underlying layer and may overestimate the temperature of surface-hoar crystals. Supposing that the vapour-pressure difference between the surface-hoar crystals and the air is zero, they would not evaporate, even during the daytime. To fulfill this requirement, the temperature of the surface-hoar crystals should be lower than the value measured by the infraredradiation thermometer. The temperature estimated becomes about $2^{\circ} \mathrm{C}$ lower on 27 December (Fig. 1), about $2^{\circ} \mathrm{C}$ on 24 February and about $5^{\circ} \mathrm{C}$ on 25 February (Fig. 4). These values are too large, although the accuracy of the device was not high and a temperature gradient within the surface-hoar layer might exist. Hence, it seems reasonable to say that the temperature of surface-hoar crystals was not so low as we have calculated. So, evaporation probably occurred on the surface-hoar crystals but the water vapour from the lower layer might have condensed on the crystals and partially made up for their decrease in size.

Hachikubo and Akitaya (1997) found a linear relationship between the condensation rate and vapour-pressure difference multiplied by wind speed, thus the surface-hoar condensation could be estimated using the bulk-transfer method from meteorological data: air temperature, snowsurface temperature, humidity and wind speed. However, this method may underestimate the vapour condensation when surface-hoar forms for several days, because it cannot evaluate the preservation of the surface hoar during the daytime. It is difficult to measure the temperature of only surface-hoar crystals without the effect of solar radiation. We need a further quantitative investigation about vapour transport in the surface layer and how surface-hoar crystals maintain their size during the daytime.

Fukuzawa and Akitaya (1993) have observed the quick growth of faceted and depth-hoar crystals just below the snow surface under radiative cooling conditions. The meteorological conditions for this kind of depth-hoar formation are similar to those of surface-hoar formation as Davis and others (1997) have pointed out. During several clear and humid nights, the layer near the surface may change into a mixture of surface-hoar and depth-hoar crystals, as observed in this study. Since the depth-hoar layer is also well known to be brittle, a layer composed of both hoar crystals has the potential to create a rather thick weak layer in the snowpack.

\section{ACKNOWLEDGEMENTS}

The authors would like to express their thanks to K. Nishimura, of the Institute of Low Temperature Science, Hokkaido University, for helpful suggestions and useful discussion. We are grateful to the staff of the Teshio Experimental Forests of Hokkaido University for their logistic support. This 
research was supported by the Fund for Avalanche Research of the Ministry of Education, Science, Culture and Sports, Japan.

\section{REFERENCES}

Colbeck, S. C. 1988. On the micrometeorology of surface hoar growth on snow in mountainous area. Boundary-Layer Meteorol., 44(1-2), 1-12.

Davis, R. E., B. Jamieson, J. Hughes and C. Johnston. 1997. Observation on buried surface hoar-persistent failure planes for slab avalanches in British Columbia, Canada. In ISSW'96. International Snow Science Workshop, 6-10 October 1996, Banff, Alberta. Proceedings. Revelstoke, B.C., Canadian Avalanche Association, 81-85.

Fukuzawa, T. and E. Akitaya. 1993. Depth-hoar crystal growth in the surface layer under high temperature gradient. Ann. Glaciol., 18, 39-45.

Hachikubo, A. and E. Akitaya. 1997. Effect of wind on surface hoar growth on snow. 7. Geophys. Res., 102(D4), 4367-4373.

Hachikubo, A., T. Fukuzawa and E. Akitaya. 1994. Formation rate of surface hoar crystals under various wind velocities. In ISSW'94. International Snow Science Workshop, 30 October - 3 November 1994, Snowbird, Utah. Proceedings. Snowbird, UT, P.O. Box 49, 132-137.

Lang, R. M., B. R. Leo and R. L. Brown. 1985. Observations on the growth process and strength characteristics of surface hoar. In ISSW'84. International Snow Science Workshop, $24-27$ October 1984, Aspen, Colorado. Proceedings. Aspen, CO, ISSW Workshop Committee, 188-195.

Oke, T. R. 1987. Boundary layer climates. Second edition. London, Methuen; New York, Routledge Press.

Perla, R. I. and M. Martinelli, Jr. 1976. Avalanche handbook. Fort Collins, CO, U.S. Department of Agriculture. Forest Service. (Agricultural Handbook 489.)

Stull, R. B. 1988. An introduction to boundary layer meteorology. Dordrecht, etc., Kluwer Academic Publishers. 